\title{
Quantitative Analysis of Aortic Valve Stenosis and Aortic Root Dimensions by Three-Dimensional Echocardiography in Patients Scheduled for Transcutaneous Aortic Valve Implantation
}

\author{
Rolf Alexander Jánosi • Björn Plicht • Philipp Kahlert • \\ Mareike Eißmann • Daniel Wendt • Heinz Jakob • \\ Raimund Erbel • Thomas Buck
}

Published online: 30 August 2014

(C) Springer Science+Business Media New York 2014

TAVI, such as underestimation of the size of the aortic annulus that can result in aortic regurgitation and dislocation of the valve, or overestimation can lead to annulus rupture.

Keywords Aortic valve stenosis - Aortic root .

Three-dimensional echocardiography · Transcutaneous aortic valve implantation · Real-time $\cdot$ Transesophageal echocardiography

\section{Introduction}

Aortic valve (AV) disease has emerged as a frequent clinical problem in the rapidly growing elderly population, with an increasing proportion of patients being at high risk for traditional AV surgery [1]. Transcatheter AV implantation (TAVI) has accordingly grown in popularity as an alternative to surgery for such high-risk patients [2]. However, since it is an interventional procedure without the benefit of a direct view of the $\mathrm{AV}$, detailed anatomical information prior to the procedure is mandatory to avoid devastating complications. Assessment of the AV area (AVA) is only the first step in the evaluation and selection of suitable patients. For prosthesis selection from a range of defined sizes and a variety of prosthesis types, the accurate measurement of aortic root geometry is essential [3, 4]. Moreover, a rare but extremely critical complication is the intraoperative occlusion of the coronary ostium, which underlines the importance of prior evaluation of the distance from the aortic annulus to the coronary ostia [5]. Finally, paravalvular regurgitation - which is known to be associated with higher mortality in patients undergoing TAVI — can be avoided by correct prosthesis sizing and positioning when the aortic root dimensions are known [6].

The major reasons for the regular use of echocardiography in the clinical setting and for follow-up assessment are its 
availability, lack of relevant procedure-related risks, and low cost as compared to invasive techniques and cardiovascular magnetic resonance imaging (MRI). The indications for surgery are based on symptoms and the severity of AV stenosis (AS); in current guidelines, this is defined as an AVA of less than $1 \mathrm{~cm}^{2}\left(<0.6 \mathrm{~cm}^{2} / \mathrm{m}^{2}\right)$ or a mean AV gradient $\geq 40 \mathrm{mmHg}$ $[1,7-9]$. Two-dimensional transthoracic echocardiography (2D-TTE) is now typically used as the first step in quantification of AS, based on the determination of flow-dependent variables using the continuity equation (CE) and the effective AVA [10]. However, in patients with subvalvular obstruction, reduced left ventricular function, or aortic regurgitation, the accurate assessment of AS may be difficult [11]. Multiplane transesophageal echocardiography (TEE) is known to provide more exact information by allowing direct planimetric quantification of the AVA. One of the difficulties of this procedure is obtaining the correct cross-sectional 2D short-axis view at the tip of the AV cusps due to the motion of the aortic annulus and valve cusps, which may result in overestimation of the AVA $[12,13]$. The use of real-time 3D-TEE (RT3D-TEE) may lead to better results than standard 2D-TEE because of the use of a $3 \mathrm{D}$ volume dataset of the $\mathrm{AV}$, where the true orthogonal imaging plane of the aortic cusps can be measured directly or analyzed later by an experienced echocardiographer [14]. Moreover, RT3D-TEE is less time-consuming and does not have limitations, such as those faced when using other 3D techniques such as computed tomography (CT) and MRI [15].

For the calculation of AVA by echocardiography using the $\mathrm{CE}$, the determination of the left ventricular outflow tract (LVOT) cross-sectional area (LVOTA) is necessary. AVA is usually estimated using CE, including the LVOTA calculated from a measured LVOT diameter (LVOTD) with the assumption that the LVOT is circular [7]. Measurements using CE have shown good agreement with those using invasive techniques; however, consistent underestimation is noted since the commonly used formulation of the CE relies on the assumption of a circular LVOT [16].

The aortic root is the direct continuation of the LVOT, beginning from the insertion of the aortic valvular cusps to the level of the sinotubular junction [4]. Its anatomy and diameter vary in patients with AS or aortic regurgitation as well as in the healthy population [17]. The measurement of the aortic annulus is the key measurement for the preparation of patients undergoing TAVI. Undersizing may lead to prosthesis migration or paravalvular regurgitation [18]. Even oversizing may cause problems such as complications related to vascular access, due to the delivery system or insufficient expansion of the prosthesis, reducing the valve's durability [4]. We have previously described a method for the rapid, detailed 3D measurement of the aortic annulus using the ability of 3D measurements to identify the accurate diameter [19]. The aortic annulus should typically be measured in systole between the insertion of the AV cusps, not including the calcification of the aortic cusps (Fig. 1) [19, 20••]. Particularly when the annulus diameter is in the borderline range, the use of RT3D-TEE with analysis of volumetric data is helpful.

Piazza et al. [4] defined four parts of the aortic root: a virtual annulus formed by the joining basal attachments of the AV leaflets, the anatomic annulus formed by the ventriculoarterial junction, the sinotubular junction, and a crown-like ring formed by the insertion of the leaflets. Thus the structure of the aortic annulus as measured by echocardiographic means is the virtual ring or the hinge point of the $\mathrm{AV}$ cusps (Fig. 2).

In this study, we tested the hypothesis that the LVOT is circular, based on a formula for eccentricity, and its impact on the calculation of AVA using the CE in comparison to direct planimetry. Further, in this context, we studied the geometry of the LVOT and AV in patients undergoing TAVI at our institution.

\section{Subjects and Methods}

2D-TTE, 2D-TEE, and RT3D-TEE echocardiography were performed using a commercial ultrasound imaging system (iE33; Philips Medical Systems, Andover, MA) with 2D matrix S5-1 and a 3D matrix-array transesophageal transducer $(\mathrm{X} 7-2 \mathrm{t})$. The examination protocol was as previously described [19] and is further documented in Fig. 1.

The study group comprised 71 patients undergoing 2D-TTE, 2D-TEE, and RT3D-TEE for evaluation as candidates for TAVI. The 2D-TTE protocol included a complete transthoracic echo-Doppler study with colorpulsed and continuous-wave Doppler measurements of the AV [21]. The LV end-systolic and LV end-diastolic volume indices were calculated using the Simpson biplane method of discs [21].

Routine 2D-TTE was followed by 2D-TEE and 3DTEE full-volume acquisitions. All images were digitally stored for offline analysis (QLAB; Philips Medical Systems). For the acquisition of the volumetric 3D datasets, the live 3D zoom function was used to gain a magnified zoomed image of the aortic root in the $35^{\circ}$ short-axis or $120^{\circ}$ long-axis view.

AVA was calculated by 2D-TTE-derived flow methods (AVA was calculated using the CE and the time-velocity integral of AV and LVOT spectral Doppler curves): in TEE using the standard 2D-TEE planimetry method, and in 3D the planimetric AVA was extracted from volumetric 3D datasets using RT3D-TEE. In both methods, planimetry was repeated three times and values were averaged [22]. 2D measurement of the LVOTD was obtained $0.5-1.0 \mathrm{~cm}$ below the $\mathrm{AV}$ when the aortic cusps were maximally separated, and the approximated cross-sectional area of the LVOT was calculated as $\pi \times r^{2}$ [7]. For the CE-derived calculation of LVOT, the systolic LVOTD 

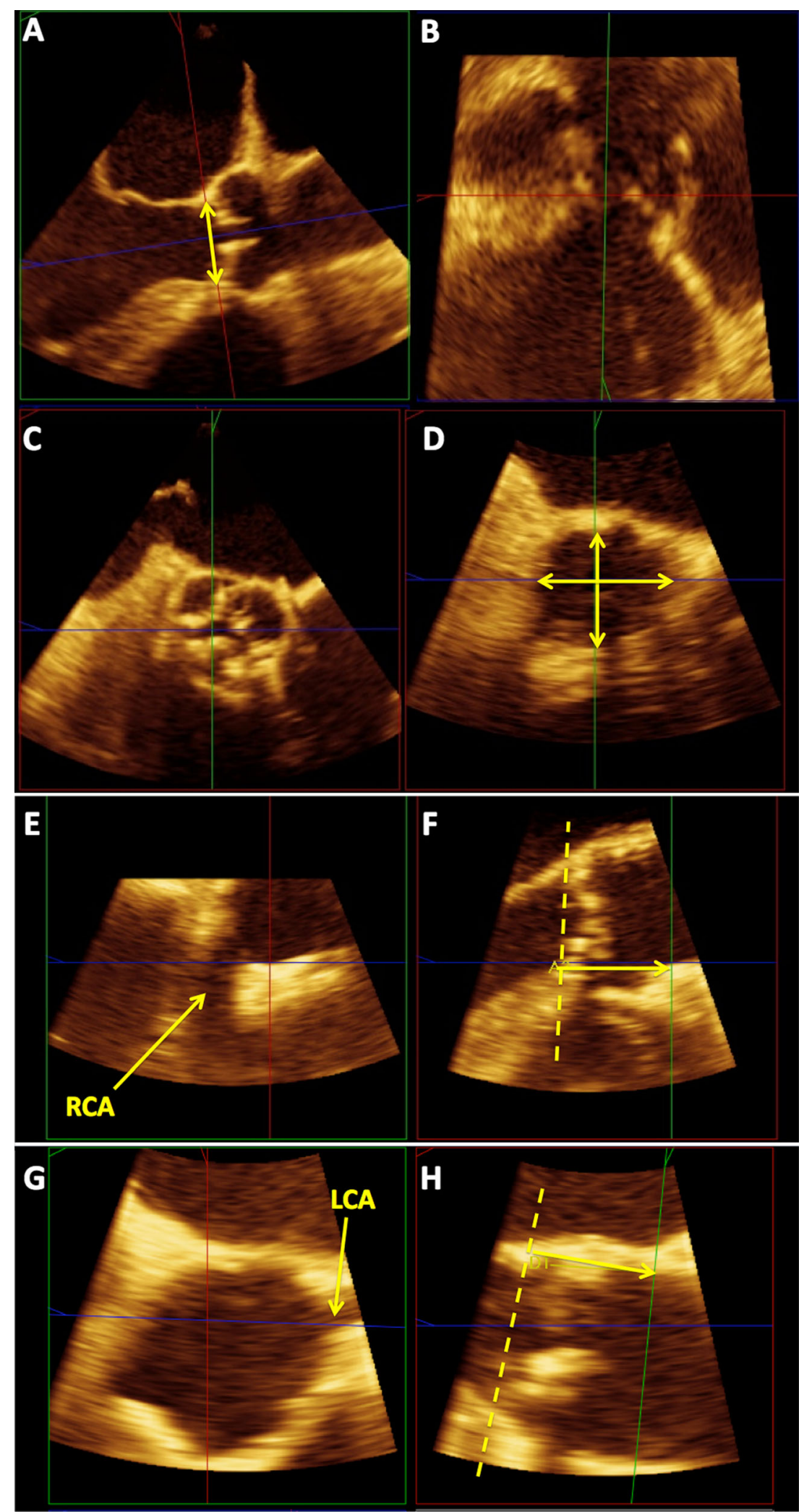

Fig. 1 Measurement of the aortic root by RT3D-TEE. From a live 3D zoom dataset, two orthogonal long-axis views of the aortic valve were positioned in the multiplanar reconstruction mode (a sagittal, b coronal). Using a third plane, the cross-sectional view of the aortic valve for correct tracing of the aortic valve area was selected $(\mathbf{c})$. The aortic valve area was traced at the moment of maximal systolic opening. Then the short-axis view was shifted to the level of the aortic annulus, where the annular area and maximum and minimal diameters were measured (d). Finally, by adjusting the imaging plane within the long-axis view, the distance between the aortic annulus and coronary ostia could be measured (e, $\mathbf{f}$ RCA; $\mathbf{g}, \mathbf{h}$ LCA) 
Fig. 2 a Three-dimensional model of the aortic root showing the location of the various annular rings and junctions. $\mathbf{b}$ The close relationship between these structures and the coronary ostia can be seen (reprinted with kind permission from Piazza et al. [4])
A

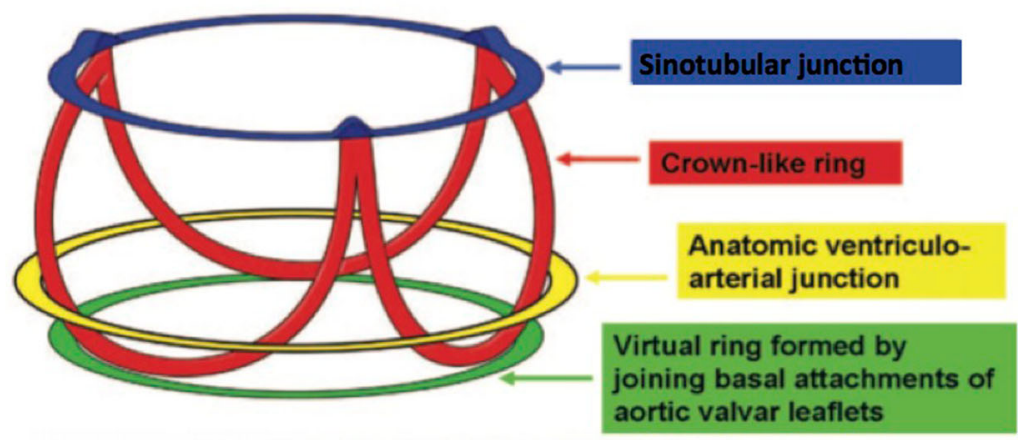

B

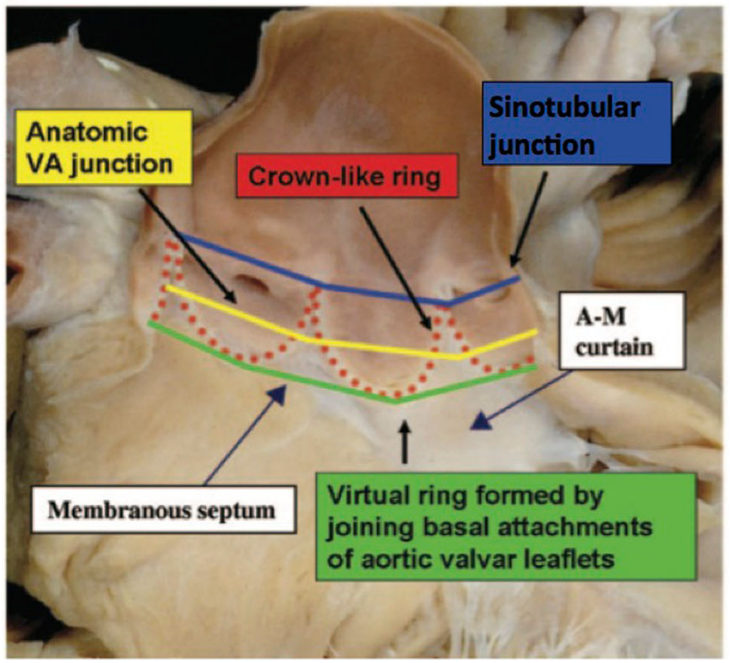

was introduced into the equation: $\mathrm{LVOTAc}=\pi \times(d / 2)^{2}$. In contrast, in 3D using RT3D-TEE, direct planimetry for LVOT was performed again $0.5-1.0 \mathrm{~cm}$ below the AV (LVOTAp).

An eccentricity index (EI) was calculated using the shortest and longest LVOTDs (EI=1-LVOTD short $\left./ \mathrm{LVOTD}_{\text {long }}\right)$ [23]. Similarly, an EI was used for the aortic annular area. For CE, the assumed perfect circle would be represent by an EI of zero, and an ellipsoid shape by a higher EI.

\section{Real-time 3D Transesophageal Echocardiography}

Loops were viewed after acquisition to ensure that the live 3D zoom data included LVOT and AV measurements. These fullvolume DICOM loops were analyzed using QLAB. First, the orientation of an imaging plane within the 3D full volume was manipulated to gain an LVOT plane aligned parallel and about $0.5-1.0 \mathrm{~cm}$ below the AV. Planimetry was then performed by tracing the outline of the LVOT. Second, in multiplanar reconstruction mode, two orthogonal long-axis views of the AV and ascending aorta were selected; then a third plane perpendicular to the long-axis view was moved to the smallest $\mathrm{AV}$ orifice area at the moment of maximal aortic valve opening. Subsequently, the annulus was then measureed by shifting the short-axis to show the aortic annulus, where the minimum and maximum diameters and annulus area were measured. The correct level of the aortic annulus was defined as the lowest plane of the valve hinge-point (inferior virtual basal ring) [4]. In addition, as a third step, in an end-diastolic frame using two different imaging planes, the distances from the ostia of the left and right coronary arteries (LCA and RCA) to the annulus were measured. The measurement procedures are illustrated in Fig. 1.

Written informed consent was obtained from all patients at the time of consent for the clinical TEE procedure.

\section{Statistical Analysis}

Continuous data are expressed as means $\pm \mathrm{SD}$. Categorical data are presented as percentages. Pearson's correlation coefficient and variability were calculated. Variables were compared using a paired $t$-test. Values of $P<0.05$ were considered statistically significant.

\section{Results}

The baseline characteristics of the study population are shown in Table 1. 
Table 1 Baseline clinical and 2D echocardiographic characteristics of the 71 study patients

\begin{tabular}{ll}
\hline Variable & Value \\
\hline Age (years) & $75 \pm 13$ \\
Body surface area $\left(\mathrm{m}^{2}\right)$ & $1.83 \pm 0.21$ \\
Body mass index $\left(\mathrm{kg} / \mathrm{m}^{2}\right)$ & 30.6 \\
Left ventricular ejection fraction $(\%)$ & $47 \pm 13$ \\
Aortic valve area $\left(\mathrm{m}^{2}\right)$ & $0.71 \pm 0.26$ \\
Mean transaortic pressure gradient $(\mathrm{mmHg})$ & $39.9 \pm 21.5$ \\
Peak transaortic pressure gradient $(\mathrm{mmHg})$ & $67.3 \pm 34.5$ \\
LV end-diastolic diameter (mm) & $52.2 \pm 9.7$ \\
\hline
\end{tabular}

\section{LVOT Eccentricity and LVOTA}

LVOTD $_{\text {long }}$ was significantly greater than LVOTD $_{\text {short }}$ by a mean of $0.32 \pm 0.21 \mathrm{~cm}(P<0.001)$. LVOTA was significantly greater than LVOTA $_{\mathrm{c}}\left(3.51 \pm 0.82 \mathrm{~cm}^{2}\right.$ vs. $3.24 \pm 1.07 \mathrm{~cm}^{2}$; $P<0.001)$. Using the equation of an ellipse $(\pi \times a \times b)$, the LVOTA 3Dellip $\left[=\pi \times\left(\right.\right.$ LVOTD $\left._{\text {short }}\right) / 2 \times\left(\right.$ LVOTD $\left.\left._{\text {long }}\right) / 2\right]$ was comparable to LVOTA $\left(3.25 \pm 1.17 \mathrm{~cm}^{2}\right)$, resulting in improved agreement with $\operatorname{LVOTA}_{p}(r=0.97)$. The mean EI was $0.14 \pm$ 0.10 , with most patients showing some degree of eccentricity.

\section{Measurement of AVA}

The mean AVA calculated by 2D-TTE was $0.69 \pm 0.28 \mathrm{~cm}^{2}$ with peak and mean pressure gradients across the AV of $67.3 \pm$ 34.5 and $39.9 \pm 21.5 \mathrm{mmHg}$, respectively (Table 1). A high correlation was noted between the planimetry of AVA by 2DTEE and RT3D-TEE $(r=0.81, P<0.1)$; however, 2D-TEE planimetry showed a significantly larger AVA than RT3DTEE $\left(0.71 \pm 0.26 \mathrm{~cm}^{2}\right.$ vs. $\left.0.61 \pm 0.23 \mathrm{~cm}^{2}, P<0.05\right)$; Fig. 2$)$. Figure 3 shows different imaging planes for the same AV, demonstrating the reason for the overestimation of AV size. Further, considering the RT3D-derived LVOTA $_{p}$ in the CE yielded a higher calculated AVA $\left(0.8 \pm 0.58 \mathrm{~cm}^{2}\right)$ (Fig. 4).

\section{Aortic Annulus Diameter and Area}

The mean minimal and maximal diameters of the aortic annulus measured by RT3D-TEE were comparable to those published in previous reports [24] (Table 2). The aortic annulus diameter was measured by 2D-TTE, 2D-TEE, and RT3DTEE, and the annulus area was measured by 2D-TEE and RT3D-TEE successfully in all patients. The aortic annulus area measured by 2D-TEE was significantly smaller than that calculated by RT3D-TEE $\left(3.63 \pm 0.72 \mathrm{~cm}^{2}\right.$ vs. $4.05 \pm 0.71 \mathrm{~cm}^{2}$; $P<0.05$ ). There was a high correlation between the planimetry estimated by 2D-TEE and RT3D-TEE $(r=0.81)$. The RT3DTEE data underlined again that the aortic annulus has an ellipsoid shape and is not circular.
Distances from the Coronary Ostia to the Aortic Annulus

The distances from the ostia of the LCA and RCA to the aortic annulus could be measured in $92 \%$ and $86 \%$ of the patients, respectively. The mean distance from the LCA ostium to the aortic annulus was $12.1 \pm 3.7 \mathrm{~mm}$ and from the RCA ostium to the aortic annulus was $15.3 \pm 3.7 \mathrm{~mm}$, with large ranges of 7 $21 \mathrm{~mm}$ and $7.9-24 \mathrm{~mm}$, respectively.

\section{Discussion}

In the current study, we demonstrated the feasibility of direct evaluation using RT3D-TEE for measuring the AV and aortic root and demonstrated that the aortic annulus and LVOT are oval in shape.

Our findings are consistent with those of previous studies showing that LVOTA is significantly underestimated by $2 \mathrm{D}$ minor axis measurements as compared with 3D data and that the geometry of the LVOTA is best described as elliptical and is rarely circular [23].

The accuracy in estimating AVA using the CE depends on the exact measurement of LVOTD and the correct placement of the pulsed Doppler flow immediately below the AV. Errors in the measurement of the diameter are squared in the process of calculating AVA [25], leading to an underestimation of up to $13 \%$ for LVOTA and $26.3 \%$ for AVA due to the multiplicative relationship between these two terms [26]. These findings are in agreement with those of other studies using CT [23, 26] and MRI [27]. This can lead to a reclassification of up to $25 \%$ of patients having moderate AS when using AVA calculated by RT3D-TEE [26]. Thus, knowledge of the LVOT geometry is crucial for potential TAVI patients, affecting the success of the procedure [28]. The accurate measurement of LVOTA is moreover important in the assessment of shunt ratios for hypertrophic cardiomyopathy and in the evaluation of subaortic membranes [29].

Nakai et al. showed the dynamic movements of the aortic annulus during the cardiac cycle in speckle tracking analysis, with a more cranial position in early systole and a more caudal position during isovolumetric relaxation [12]. Different approaches for the exact estimation of the AVA include: (1) planimetric measurement from selected slices extracted from a volumetric 3D-TEE dataset, and (2) flow-derived calculation of AVA using the CE after 3D evaluation of the LVOTA. This may lead to a more accurate estimation than 2D-TEE since this method is limited by difficulties in selecting the correct cross-sectional view of the tip of the aortic cusps [12, 13, 30]. RT3D-TEE enables rapid data acquisition even of huge volumetric datasets for later accurate evaluation [31]. We favor using the live 3D zoom mode during the collection of the volumetric dataset, which helps reduce artifacts. 

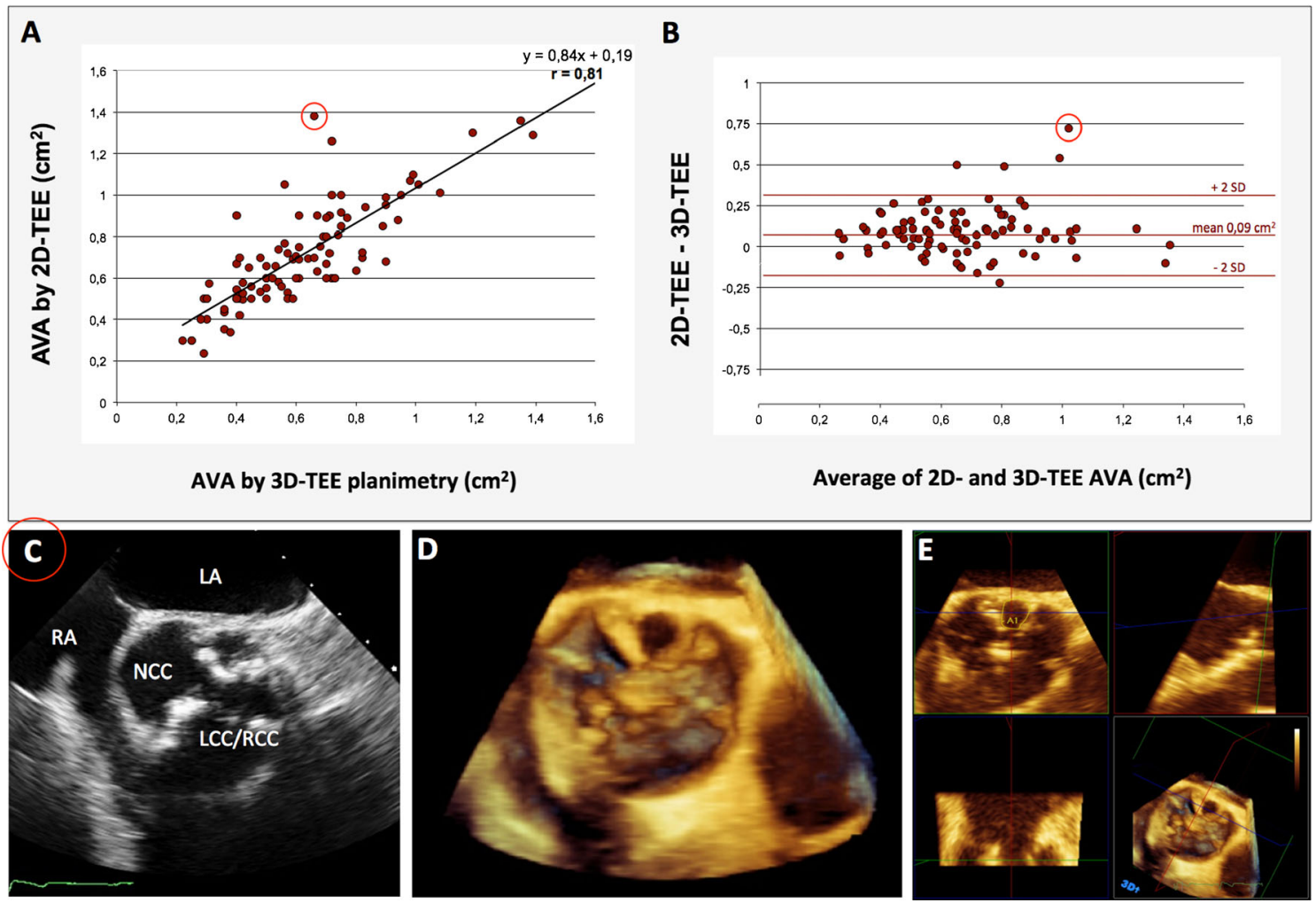

Fig. 3 a, b Linear correlation between the aortic valve (a) area and Bland-Altman analysis between RT3D-TEE and 2D-TEE (b). c A 2DTEE image of a severely calcified aortic valve. $\mathbf{d}$ Live $3 \mathrm{D}-\mathrm{TEE}$ reveals the original tricuspid valve with a funnel-shaped valvular opening. e

Quantification of the exact valvular opening area. Red circles in $\mathbf{b}$ and c: The funnel-shaped valve results in overestimation of the aortic orifice area and underestimation of the aortic stenosis in 2D-TEE [14]

Fig. 4 Overestimation of AVA by 2D-TEE. Before valve replacement is considered, the severity of stenosis must be accurately assessed. It is important to determine AVA using a flow-independent technique such as planimetry. In 2D methods, it is often difficult to capture the tip of the aortic valve leaflets at the moment of maximal systolic opening; this may lead to overestimation of AVA because of a "funnel" configuration. The example images show the imaging planes of a RT3D-TEEacquired volumetric dataset with long-axis views (left) and en face views (right). Usual 2D planimetry at different levels could result in the different AVA dimensions of $1.15 \mathrm{~cm}^{2}$ and $0.75 \mathrm{~cm}^{2}$. This illustrates that optimal positioning of the imaging plane is essential for accurate planimetry of AVA

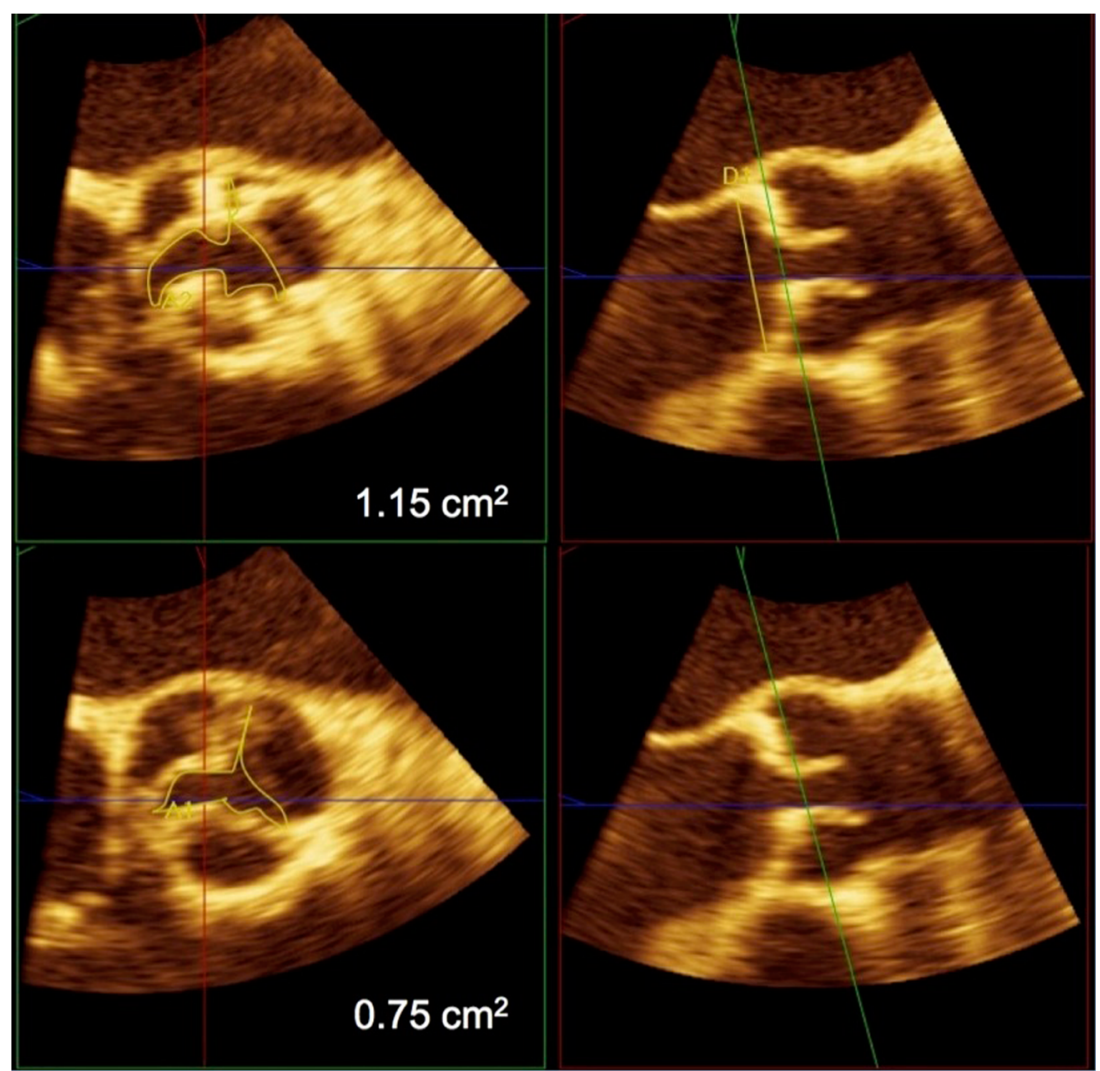


Table 2 Aortic valve area calculated by planimetry and the continuity equation, and comparison of three imaging methods for measuring the aortic annulus and area

\begin{tabular}{llll}
\hline Variable & 2D-TTE & 2D-TEE & RT3D-TEE \\
\hline Aortic valve area $\left(\mathrm{cm}^{2}\right)$ & & & \\
$\quad$ Planimetry & $0.82 \pm 0.32^{*}$ & $0.71 \pm 0.26^{*}$ & $0.61 \pm 0.23^{*}$ \\
$\quad$ Continuity equation & $0.69 \pm 0.28$ & $0.75 \pm 0.39$ & $0.8 \pm 0.58$ \\
Aortic annulus & $21.3 \pm 3.0$ & $22.3 \pm 2.9$ & $22.0 \pm 3.0$ \\
$\quad$ Maximum diameter (mm) & & & $24.1 \pm 3.9$ \\
Minimum diameter $(\mathrm{mm})$ & & & $21.3 \pm 4.4$ \\
EI & & & $0.15 \pm 0.14$ \\
Area (cm ${ }^{2}$ ) & & & $4.04 \pm 0.71$ \\
LVOT & & & $21.6 \pm 3.6$ \\
Maximum diameter (mm) & $19.6 \pm 2.3$ & & $18.5 \pm 3.5$ \\
Minimum diameter (mm) & & $0.14 \pm 0.10$ \\
EI & & & $3.24 \pm 1.07$ \\
Area (cm ${ }^{2}$ ) & $2.94 \pm 0.44$ & & $12.1 \pm 3.7$ \\
Distance to coronary artery ostia (mm) & & $15.3 \pm 3.7$ \\
LCA & & \\
RCA & &
\end{tabular}

${ }^{*} P<0.05$ versus continuity equation value in each method, paired $t$-test

3D echocardiography may facilitate the accurate measurement of the aortic annulus and significantly reduce interobserver and intraobserver variability in comparison to $2 \mathrm{D}$ techniques [19]. This is because the 2D long-axis view (sagittal view) of the aortic annulus is difficult to align in the center of the annulus using only $2 \mathrm{D}$ techniques, as recently described by Piazza et al. [4]. Ng et al. demonstrated that aortic annular areas are more significantly underestimated by 2D-TEE than by 3DTEE in comparison to the "gold standard" multislice CT (MSCT), and that such underestimation decreases after TAVI when the annular areas change to a more circular shape [26].

Previously, cardiologists and cardiac surgeons have hesitated employing TAVI in patients with bicuspid AVs. However, newer patient registries have shown that TAVI can be performed in such patients with satisfactory results despite a higher rate of relevant aortic regurgitation. 3D echocardiography can provide important information in such patients, as recent reports have shown that patients with bicuspid AS have larger transverse areas and longitudinal distances [32], helping to reduce unnecessary paravalvular leakage in the future.

\section{Distances from the Coronary Ostia to the Aortic Annulus}

In 2D-TEE examinations, the distance from the RCA ostium to the annulus can be evaluated but it is rarely possible to measure the distance from the LCA ostium to the annulus as the LCA ostium usually lies in a different coronal plane is not accessible by 2D imaging. 3D-TEE may be an alternative for the evaluation of these distances instead of the typically used multidetector CT (MDCT), especially in patients with renal dysfunction, as earlier studies have shown good correlations for these techniques $[24,33]$. In previous studies, MDCT measurements yielded an average distance from the aortic annulus to the coronary ostia from $12.8 \pm 3.5$ to $13.4 \pm$ $3.2 \mathrm{~mm}$ for the LCA and from $13.2 \pm 1.8$ to $16 \pm 2.8 \mathrm{~mm}$ for the RCA [34-36]. Others have evaluated only the distance to the LCA ostium and reported a distance of $13.5 \pm 2.2 \mathrm{~mm}[37 \cdot$ ] with correlations of $r=0.83(P<0.001)$ for RT3DTEE vs. MDCT. We have also evaluated the distance from the aortic annulus to the RCA ostium, which although possible more rarely than for the LCA, is possible in $86 \%$ of patients, but only few data have been published regarding the RCA ostium $[20 \bullet \cdot$. However, as the distance from the aortic annulus to the RCA ostium is usually greater, its occlusion is likely to be more uncommon.

Especially in patients with extensive calcification of the AV, which impairs exact measurement of the annulus-coronary ostium distance due to artifacts, RT3D-TEE poses certain disadvantages in comparison to other imaging modalities. An annulus-coronary ostium distance of less than $10 \mathrm{~mm}$ increases the risk of coronary occlusion during TAVI [4, 38, 39]. In addition, several studies have shown that the distance from the aortic annulus to the coronary artery ostia is reduced in patients with AS [17, 24, 34]. Measurement of the annuluscoronary ostium distance is also included in the expert consensus document of the European Association of Echocardiography and American Society of Echocardiography [20••].

In our study, accurate measurement of the distance from the aortic annulus to the LCA ostium was possible in $92 \%$ of the patients, while others have found a feasibility up to $97.5 \%$ [37•]. Tamborini et al. also demonstrated the use of RT3DTEE for immediate postoperative evaluation of the distance from the LCA ostium to the aortic prosthesis, which was feasible in about $90 \%$ of patients [37•]. Recently it was demonstrated that CT-based measurements differ from the corresponding intraoperative measurements [36]. But undoubtedly, knowing that the distance from the aortic annulus and coronary ostia is small is highly valuable for the surgeon, who can take additional care in positioning the prosthesis.

Recently increasing attention has been paid to the evaluation of the lengths of the $\mathrm{AV}$ cusps in relation to the distance to the ostia $[17,37 \cdot]$. If they are greater than the distance from the aortic annulus to the coronary ostia, the patient is at risk of ostial coronary occlusion by the cusp when the valve is implanted.

\section{Conclusions}

The shape of the LVOT and the annulus is more frequently elliptical and not circular, which may lead to significant 
underestimation of the true LVOT and aortic annulus areas. RT3D-TEE provides accurate estimation of the AVA and quantification of the aortic root, with important clinical implications for the exact estimation of the AVA and annulus area for optimal selection of prosthetic valves. An advantage of RT3D-TEE is that it can be performed at the bedside or directly before or even after prosthetic valve implantation for the evaluation of the implanted prosthesis, e.g., for identifying paravalvular regurgitation. Moreover, it is a good alternative to MDCT, particularly when it is essential to decrease the burden of contrast agent administration as in patients with compromised renal function - thereby potentially reducing the incidence of acute kidney failure [40] —as well as in patients with cardiac arrhythmia. RT3D-TEE may be performed immediately before and after procedures in the hybrid operating room $[37 \bullet, 41]$.

\section{Compliance with Ethics Guidelines}

Conflict of Interest Björn Plicht received lecture honoraria from Abbott Vascular, Wetzlar, Germany, and travel expenses and lecture honoraria from Philips Medical.

Philipp Kahlert received personal fees from Edwards Lifesciences Inc. Rolf Alexander Jánosi, Mareike Eißmann, Daniel Wendt, Heinz Jakob, Raimund Erbel, and Thomas Buck declare that they have no conflict of interest.

Human and Animal Rights and Informed Consent This article does not contain any studies with human or animal subjects performed by any of the authors.

\section{References}

Papers of particular interest, published recently, have been highlighted as:

- Of importance

•- Of major importance

1. Camm AJ, Lip GY, De Caterina R, Savelieva I, Atar D, Hohnloser G, et al. 2012 focused update of the ESC Guidelines for the management of atrial fibrillation: an update of the 2010 ESC Guidelines for the management of atrial fibrillation. Developed with the special contribution of the European Heart Rhythm Association. Eur Heart J. 2012;33(21):2719-47.

2. Grube E, Sinning JM, Vahanian A. The Year in Cardiology 2013: valvular heart disease (focus on catheter-based interventions). Eur Heart J. 2014;35(8):490-5.

3. Kasel AM, Cassese S, Bleiziffer S, Amaki M, Hahn RT, Kastrati A, et al. Standardized imaging for aortic annular sizing: implications for transcatheter valve selection. JACC Cardiovasc Imaging. 2013;6(2):249-62.

4. Piazza N, de Jaegere P, Schultz C, Becker AE, Serruys PW, Anderson RH. Anatomy of the aortic valvar complex and its implications for transcatheter implantation of the aortic valve. Circ Cardiovasc Interv. 2008;1(1):74-81.

5. Webb JG, Pasupati S, Humphries K, Thompson C, Altwegg L, Moss R, et al. Percutaneous transarterial aortic valve replacement in selected high-risk patients with aortic stenosis. Circulation. 2007;116(7):755-63.

6. Patsalis PC, Konorza TFM, Al-Rashid F, Plicht B, Riebisch M, Wendt $\mathrm{D}$, et al. Incidence, outcome and correlates of residual paravalvular aortic regurgitation after transcatheter aortic valve implantation and importance of haemodynamic assessment. EuroIntervention. 2013;8(12):1398-406.

7. Baumgartner H, Hung J, Bermejo J, Chambers JB, Evangelista A, Griffin BP, et al. Echocardiographic assessment of valve stenosis: EAE/ASE recommendations for clinical practice. Eur J Echocardiogr. 2009;10(1):1-25.

8. Vahanian A, Baumgartner H, Bax J, Butchart E, Dion R, Filippatos $\mathrm{G}$, et al. Guidelines on the management of valvular heart disease: The Task Force on the Management of Valvular Heart Disease of the European Society of Cardiology. Eur Heart J. 2006;28(2):230 68.

9. Gersh BJ, Maron BJ, Bonow RO, Dearani JA, Fifer MA, Link MS, et al. $2011 \mathrm{ACCF} / \mathrm{AHA}$ Guideline for the Diagnosis and Treatment of Hypertrophic Cardiomyopathy: A Report of the American College of Cardiology Foundation/American Heart Association Task Force on Practice Guidelines. Circulation. 2011;124(24): e783-831.

10. Zoghbi WA, Farmer KL, Soto JG, Nelson JG, Quinones MA. Accurate noninvasive quantification of stenotic aortic valve area by Doppler echocardiography. Circulation. 1986;73(3):452-9.

11. Grayburn PA. Assessment of low-gradient aortic stenosis with dobutamine. Circulation. 2006;113(5):604-6.

12. Nakai H, Takeuchi M, Yoshitani H, Kaku K, Haruki N, Otsuji Y. Pitfalls of anatomical aortic valve area measurements using twodimensional transoesophageal echocardiography and the potential of three-dimensional transoesophageal echocardiography. Eur J Echocardiogr. 2010;11(4):369-76.

13. Bernard Y, Meneveau N, Vuillemenot A, Magnin D, Anguenot T, Schiele F, et al. Planimetry of aortic valve area using multiplane transoesophageal echocardiography is not a reliable method for assessing severity of aortic stenosis. Heart. 1997;78(1):68-73.

14. Plicht B, Janosi RA, Kahlert P, Buck T, Erbel R. Aortic valve with 'calcified valvular stenosis': precise clarification of morphology and severity using transesophageal three dimensional echocardiography. Herz. 2008;33(4):315-6.

15. La Morena DG, Saura D, Oliva MJ, Soria F, Gonzalez J, Garcia M, et al. Real-time three-dimensional transoesophageal echocardiography in the assessment of aortic valve stenosis. Eur J Echocardiogr. 2010;11(1):9-13.

16. Garcia D, Dumesnil JG, Durand L-G, Kadem L, Pibarot P. Discrepancies between catheter and Doppler estimates of valve effective orifice area can be predicted from the pressure recovery phenomenon. J Am Coll Cardiol. 2003;41(3):435-42.

17. Calleja A, Thavendiranathan P, Ionasec RI, Houle H, Liu S, Voigt I, et al. Automated quantitative 3-dimensional modeling of the aortic valve and root by 3-dimensional transesophageal echocardiography in normals, aortic regurgitation, and aortic stenosis: comparison to computed tomography in normals and clinical implications. Circ Cardiovasc Imaging. 2013;6(1):99-108.

18. Detaint D, Lepage L, Himbert D, Brochet E, Messika-Zeitoun D, Iung B, et al. Determinants of significant paravalvular regurgitation after transcatheter aortic valve implantation. JACC Cardiovasc Interv. 2009;2(9):821-7.

19. Janosi RA, Kahlert P, Plicht B, Wendt D, Eggebrecht H, Erbel R, et al. Measurement of the aortic annulus size by real-time threedimensional transesophageal echocardiography. Minim Invasive Ther Allied Technol. 2011;20(2):85-94.

20.• Zamorano JL, Badano LP, Bruce C, Chan KL, Goncalves A, Hahn $\mathrm{RT}$, et al. EAE/ASE recommendations for the use of echocardiography in new transcatheter interventions for valvular heart disease. Eur J Echocardiogr. 2011;12(8):557-84. The current recommendations 
for the use of echocardiography in transcatheter interventions for valvular heart disease developed by the European Association of Echocardiography (EAE) and the American Society of Echocardiography (ASE).

21. Buck T, Breithardt O-A, Faber L, Fehske W, Flachskampf FA, Franke A, et al. Manual zur Indikation und Durchführung der Echokardiographie. Clin Res Cardiol Suppl. 2009;4 Suppl 1:3-51.

22. Khaw AV, Bardeleben RS, Strasser C, Mohr-Kahaly S, Blankenberg S, Espinola-Klein C, et al. Direct measurement of left ventricular outflow tract by transthoracic real-time 3D-echocardiography increases accuracy in assessment of aortic valve stenosis. Int J Cardiol. 2009;136(1):64-71.

23. Doddamani S, Grushko MJ, Makaryus AN, Jain VR, Bello R, Friedman MA, et al. Demonstration of left ventricular outflow tract eccentricity by 64 -slice multi-detector CT. Int J Cardiovasc Imaging. 2009;25(2):175-81.

24. Otani K, Takeuchi M, Kaku K, Sugeng L, Yoshitani H, Haruki N, et al. Assessment of the aortic root using real-time 3D transesophageal echocardiography. Circ J. 2010;74(12):2649-57.

25. Bednarz JE, Krauss D, Lang RM. An echocardiographic approach to the assessment of aortic stenosis. J Am Soc Echocardiogr. 1996;9(3):286-94

26. Ng AC, Delgado V, van der Kley F, Shanks M, van de Veire NRL, Bertini $\mathrm{M}$, et al. Comparison of aortic root dimensions and geometries before and after transcatheter aortic valve implantation by 2 - and 3-dimensional transesophageal echocardiography and multislice computed tomography. Circ Cardiovasc Imaging. 2010;3(1):94-102.

27. Tanaka K, Makaryus AN, Wolff SD. Correlation of aortic valve area obtained by the velocity-encoded phase contrast continuity method to direct planimetry using cardiovascular magnetic resonance. J Cardiovasc Magn Reson. 2007;9(5):799-805.

28. Saitoh T, Shiota M, Izumo M, Gurudevan SV, Tolstrup K, Siegel RJ, et al. Comparison of left ventricular outflow geometry and aortic valve area in patients with aortic stenosis by 2-dimensional versus 3-dimensional echocardiography. Am J Cardiol. 2012;109(11):1626-31.

29. Pérez De Isla L, Zamorano J, Malangatana G, Martínez Quesada M, Almeria C, Rodrigo JL. Morphological determinants of subaortic stenosis in hypertrophic cardiomyopathy: insights from real-time 3dimensional echocardiography. J Am Soc Echocardiogr. 2005;18(8):802-4.

30. Ge S, Warner JG, Abraham TP, Kon ND, Brooker RF, Nomeir AM, et al. Three-dimensional surface area of the aortic valve orifice by three-dimensional echocardiography: clinical validation of a novel index for assessment of aortic stenosis. Am Heart J. 1998;136(6): 1042-50.

31. Sugeng L, Shernan SK, Salgo IS, Weinert L, Shook D, Raman J, et al. Live 3-dimensional transesophageal echocardiography initial experience using the fully-sampled matrix array probe. J Am Coll Cardiol. 2008;52(6):446-9.

32. Wu VC, Kaku K, Takeuchi M, Otani K, Yoshitani H, Tamura M, et al. Aortic root geometry in patients with aortic stenosis assessed by real-time three-dimensional transesophageal echocardiography. J Am Soc Echocardiogr. 2014;27(1):32-41.

33. Mukherjee C, Hein F, Holzhey D, Lukas L, Mende M, Kaisers UX, et al. Is real time 3D transesophageal echocardiography a feasible approach to detect coronary ostium during transapical aortic valve implantation? J Cardiothorac Vasc Anesth. 2013;27(4):654-9.

34. Akhtar M, Tuzcu EM, Kapadia SR, Svensson LG, Greenberg RK, Roselli EE, et al. Aortic root morphology in patients undergoing percutaneous aortic valve replacement: evidence of aortic root remodeling. J Thorac Cardiovasc Surg. 2009;137(4):950-6.

35. Stolzmann P, Knight J, Desbiolles L, Maier W, Scheffel H, Plass A, et al. Remodelling of the aortic root in severe tricuspid aortic stenosis: implications for transcatheter aortic valve implantation. Eur Radiol. 2009;19(6):1316-23.

36. Wendt D, Thielmann M, Price V, Kahlert P, Kühl H, Kamler M, et al. Coronary ostium topography: an implication for transcatheter aortic valve implantation? Minim Invasive Ther Allied Technol. 2013;22(2):65-72.

37. Tamborini G, Fusini L, Gripari P, Muratori M, Cefalu C, Maffessanti F, et al. Feasibility and accuracy of 3DTEE versus CT for the evaluation of aortic valve annulus to left main ostium distance before transcatheter aortic valve implantation. JACC Cardiovasc Imaging. 2012;5(6):579-88. In a large series of patients undergoing TAVI the authors compared the feasibility and accuracy of 3D-TEE with that of CT in the measurement of left main coronary ostium to the aortic annulus distance and to the aortic prosthesis postoperatively.

38. Masson J-B, Lee M, Boone RH, Al Ali A, Al Bugami S, Hamburger J, et al. Impact of coronary artery disease on outcomes after transcatheter aortic valve implantation. Catheter Cardiovasc Interv. 2010;76(2):165-73.

39. Gautier M, Pepin M, Himbert D, Ducrocq G, Iung B, Dilly M-P et al. Impact of coronary artery disease on indications for transcatheter aortic valve implantation and on procedural outcomes. EuroIntervention. 2011;7(5):549-55.

40. Madershahian N, Scherner M, Rudolph T, Slottosch I, Grundmann F, Kuhn E, et al. Impact of sex on the risk to develop contrastinduced nephropathy after transcatheter aortic valve implantation. Innovations (Phila). 2014;9(2):87-92. discussion 92.

41. Janosi RA, Kahlert P, Plicht B, Böse D, Wendt D, Thielmann M, et al. Guidance of percutaneous transcatheter aortic valve implantation by real-time three-dimensional transesophageal echocardiography - a single-center experience. Minim Invasive Ther Allied Technol. 2009;18(3):142-8. 